\title{
Quality Management to Support Single Companies to Overcome Organisational Challenges in Collaborative Enterprise Networks
}

\author{
Patrick Sitek and Klaus-Dieter Thoben \\ BIBA Bremer Institut für Produktion und Logistik GmbH, \\ Hochschulring 20, 28359 Bremen, Germany \\ \{sit, tho\}@biba.uni-bremen.de
}

\begin{abstract}
The paper discusses organisational challenges single companies face while joining collaborative enterprise networks (EN). Following an organisational design approach in organisational differentiation and integration in EN, organisational challenges are identified. Based on steps for designing and implementing quality management systems (QMS), an initial reference model is given as potential basis for future concepts to overcome those organisational challenges.
\end{abstract}

Keywords: Collaboration, enterprise networks, organisational challenges, quality management, SME.

\section{$1 \quad$ Introduction}

The development and production of complex products in EN is carried out along value chains composed of the contributions of different single companies [1]. In case that value chains are extended across organisational boundaries, the complexity of the chains heavily increases. In order to achieve e.g. the development of products in a satisfactory timeto-market, different $\mathrm{EN}$ members are required to develop components of this new product simultaneously. In such a case, each partner of an EN is embedded in organisational relationships with identifiable counterparts. Relationships can be e.g. the need for information and material sharing, the need for consensus or a common work on a specific design. The decentralized but simultaneous way of working in such environment results into new organisational challenges for single companies.

\section{Problem to Be Solved}

Modelling value chains by dividing required product and services development on different companies and modelling inter-organisational EN structures, results in work related interdependencies and interfaces between companies [2,3,4,5,6]. An increasing division of work like in collaborative EN lead to such interdependencies and interfaces. The existence of interdependencies und interfaces again leads to a higher need for coordination as single companies might not be able to overlook all structural interdependencies and process-related interfaces. 
Following a single manufacturer scenario, it is possible to manage structural interdependencies and process-related interfaces efficiently. Customer requirements for good or service can be well defined in process descriptions and internally executed to achieve demanded characteristics of a required good or service (see Fig 1).

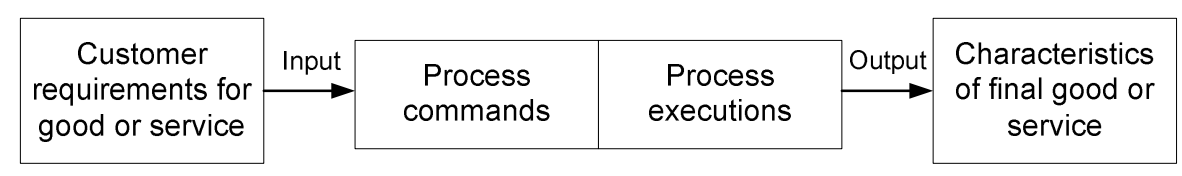

Fig. 1. Transferring customer requirements into process commands

Going one step further the same aspect can be discussed in the context of two and more manufacturers like in a supply chain cooperation. Cooperations in supply chains are characterised by a stable and fixed long-term relationship between companies based on a hierarchical buyer-seller relationship [1]. Due to a strong hierarchy it is possible for the original equipment manufacturer ("A" in Fig 2) to regulate and transfer requirements and corresponding information from customer (input) as downstream through the entire supply chain or at least to the first tier companies in the supply chain. The first tier companies ("B" and "C" in Fig 2) logically pass the requirements as significant information to the downstream tiers and receive the required goods or services back in the upstream. Divided in different supply tiers each company supplies its upstream tier with material based on strictly prior defined requirements (e.g. "D" supplies "B", "B" supplies "A" in Fig 2).

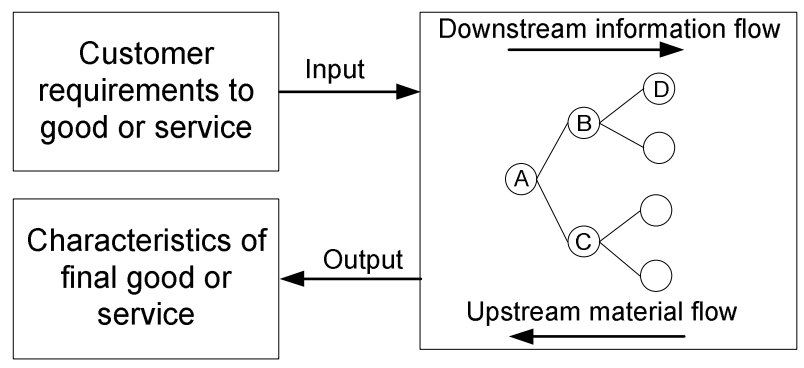

Fig. 2. Transferring requirements through a supply chain

This way customer requirements and process information can also be manageable in an inter-organisational supply chain scenario through a stricter handling of control, regulation and documentation by hierarchy. Compared to stable and long-term supply chains, EN can feature a more complex business environment, due to their dynamic behaviour. The dynamic behaviour can mainly be characterised by the organisational structure and operational processes in EN [7]. In regard of organisational structure an 
abandonment of formal and hierarchical structures is possible which results in a multitude of degrees of freedom and retention of each EN partner's autonomy. In regard of operational processes, temporary and in an extreme case uniqueness existence of processes is possible. Organisational structures and operational processes in EN are usually not determined by fixed and hierarchical partnerships of long duration. This is what makes EN so dynamic and in turn it results in a higher complexity of the business environment [8] in form of EN life-cycle phases [9]. The advances of this dynamic behaviour that accrue on the one hand are a higher flexibility and response time to the market but on the other hand they constrain stability and coordination of an organisation. Compared to the hierarchical scenario in supply chains (see Fig 2), less organisational stability and coordination in $\mathrm{EN}$ makes less manageable organisational forms possible where tracing and coordinating of customer requirements in a downstream and material flows in a upstream become more challenging (see Fig 3). The transformation of requirements (input) and the management of information flow between EN companies become more error-prone as less manageable.

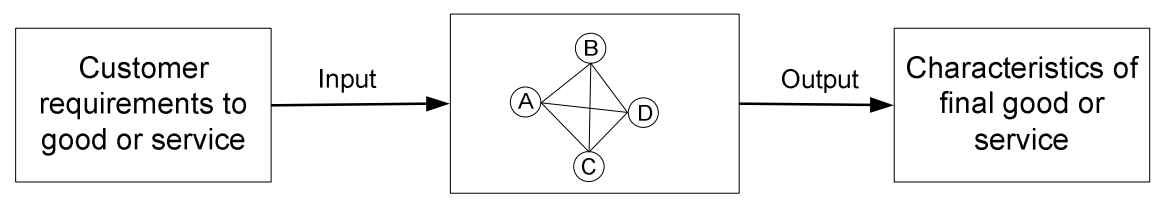

Fig. 3. Transferring requirements through an EN

\section{$3 \quad$ Findings}

To better understand the dynamic character of $\mathrm{EN}$ and the existence of relations and interdependencies between single companies in EN, this chapter discusses EN from the organisational design perspective. Organisational design is an instrument for an efficient management of companies and overall business goal achievements.

The core function of organisational design is the organisational differentiation and organisational integration [10]. The idea of organisational differentiation and integration as well as organisational structures and operational processes can be transferred for EN as shown in Fig 4. Following this, the main business job in EN is the collaboration opportunity [11]. Within the task analysis and synthesis the right companies need to be found based on their competences that matches in most promising way the fulfilment of the business job requirements. Companies possessing the right competences are linked in a network that visualises the organisational structure of the EN. Within the job analysis and synthesis the companies' individual operating value processes are identified, harmonised and integrated into an inter-organisational value or process chain that visualises the process organisation of the EN. 


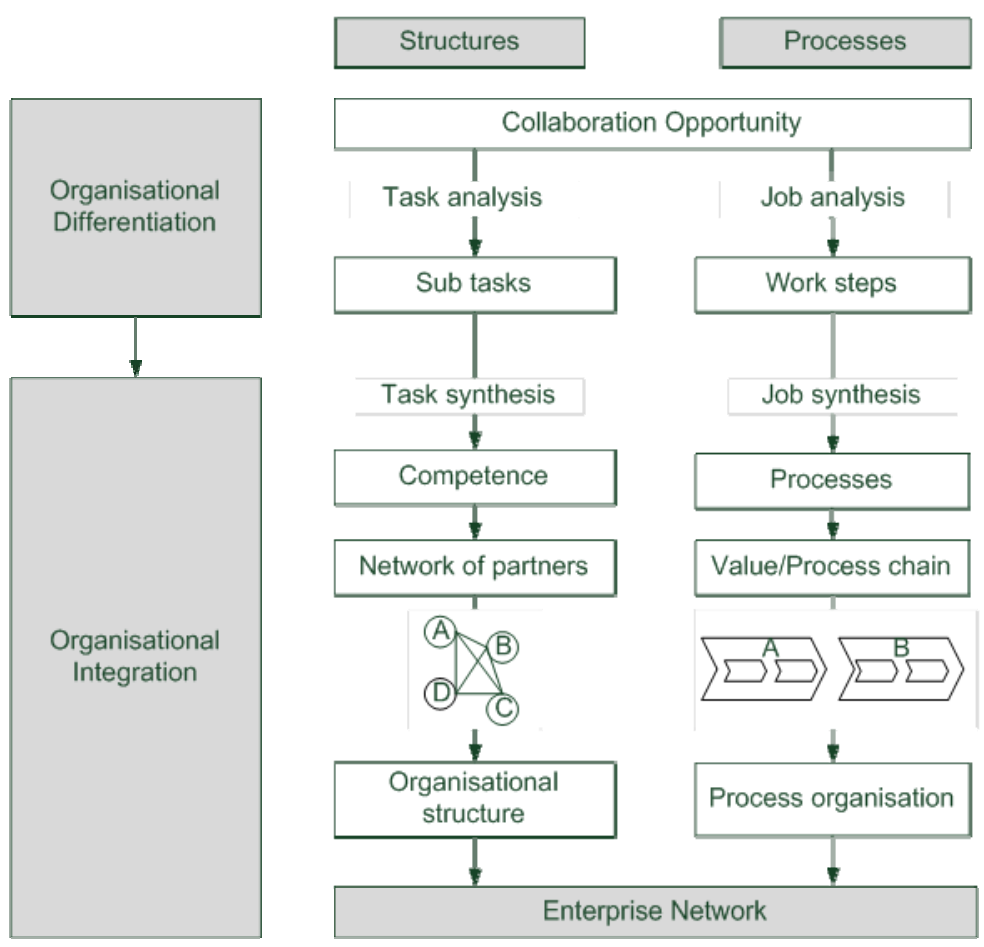

Fig. 4. Organisational differentiation and integration in EN

From operational process perspective there is the risk of not identified interfaces between companies within the inter-organisational value chain. Between two linked value adding company processes in a value chain there is an inter-organisational interface. The possibility of lack or loss of relevant information due to this interface becomes obvious (see Fig 5).

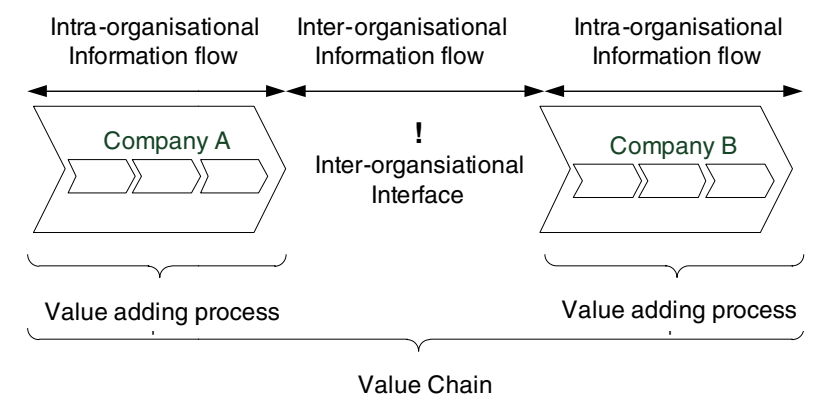

Fig. 5. Challenges on operational processes in collaborative EN

From organisational structure perspective there is the risk of not identified interdependencies between companies in an EN. Supply chains show stable, well-defined 
and by the time well-developed relations between companies. Temporarily, contractspecific and probably nonrecurring inter-organisational relations like in EN harbour a certain danger for companies not to identify all relations of a network constellation. Not identified relations lead to a wrong conclusion of the organisational structure of an EN. Fig 6 addresses a potential misinterpretation of an organisational structure for the company " $\mathrm{A}$ ". In this case company " $\mathrm{A}$ " expect three relations with other companies in a network but de facto there are four relations and also four interdependencies to be taken into account.
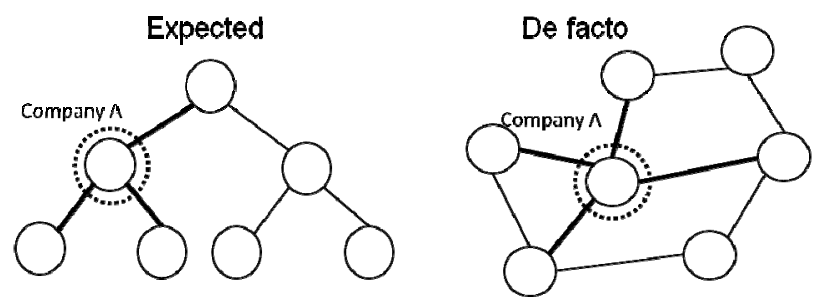

Fig. 6. Challenges on organisational structure in EN

Long-term and stable continuous production networks with a chain interdependency topology exhibit a clearer defined hierarchy with a defined relation mostly followed the material flow or a product structure logic (e.g. bill of material). Relevant information like customer requirements, product specifications and process instructions, can be easier communicated and controlled top (see Fig 2). Characterised by the absence of hierarchies keeping and respecting the autonomy of each network partner EN structures cannot be generalised and pre-defined as they are situation and case dependent. The duration of collaboration in an EN consisting of a variety of independent companies is limited, in extreme case, to one certain customer demand and the network has to be re-structured for the next demand. Summarising, while joining a collaborative EN a single company faces two main challenges:

1. Overcome of inter-organisational interfaces within the value chain of a collaborative enterprise network (operational process perspective).

2. Identification of interdependencies with other companies within the structure of a collaborative enterprise network (organisational structure perspective).

\section{$4 \quad$ Results}

To overcome these organisational challenges a quality management (QM) approach is proposed within this paper. This is due to the fact that usually companies organise their organisational objectives and management of process to realise these objectives in quality management systems (QMS). This is a new approach as mostly today's QM approaches still mostly focus on an intra-organisational perspective and or long-term oriented inter-organisational perspective [12]. 
In order to proceed towards an approach to support single companies in better managing organisational challenges in EN, it seems to be promising to bridge the two fields of EN and QM. For this purpose an initial reference model has been proposed that combines the two single and independent fields in a simplified way. Based on such a reference model the elements of future concepts to support building of organisational structure and process orientation in EN and the reduction of potential interorganisational information losses can be achieved. Following Fig 7 summarises the initial reference model combining EN and QM.

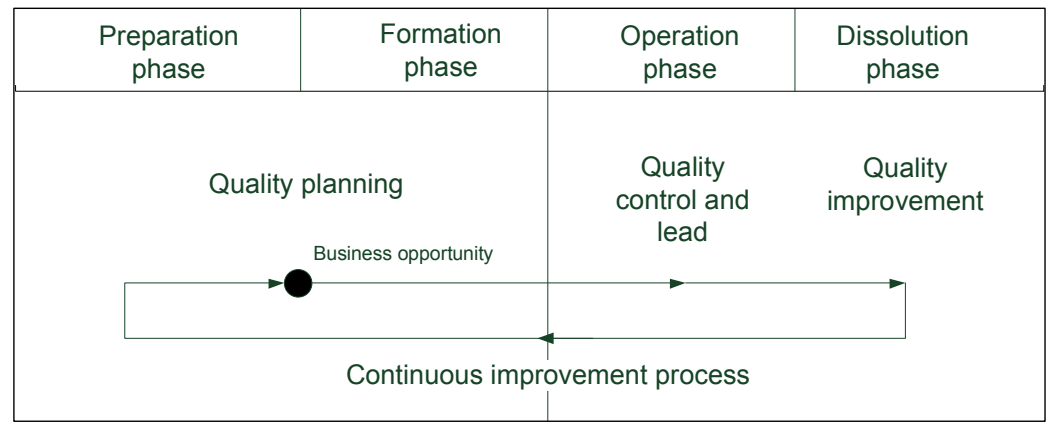

Fig. 7. Bridging EN life-cycle phases and steps for building QMS

The reference model bases on two pillars. It takes EN life-cycle phases (preparation, formation, operation and dissolution) [9] and usual steps in designing and implementing a QMS (planning, controlling, leading and improving quality) (see Table 1).

Table 1. Design and implement a QMS [13]

\begin{tabular}{|l|ll|}
\hline Quality Plan & $\begin{array}{l}\text { - } \\
\text { - }\end{array}$ & $\begin{array}{l}\text { Determining customer needs, expectations and requirements. } \\
\text { Establishing quality objectives of the organisation. } \\
\text { Determining processes, resources and responsibilities to attain } \\
\text { quality objectives. }\end{array}$ \\
\hline $\begin{array}{l}\text { Quality Con- } \\
\text { trol and Lead }\end{array}$ & $\bullet$ & $\begin{array}{l}\text { Establishing and applying methods to measure the effective- } \\
\text { ness and efficiency of processes to attain quality objectives. }\end{array}$ \\
\hline $\begin{array}{l}\text { Quality Im- } \\
\text { provement }\end{array}$ & $\begin{array}{l}\text { - } \\
\text { Eliminating nonconformities within quality objectives. } \\
\text { Establishing and applying a process for continual improve- } \\
\text { ment of processes to reach quality objectives. }\end{array}$ \\
\hline
\end{tabular}

The preparation phase of EN offers a proper timing for companies to determine and promote their competences that might be interesting for other business partners. Doing so it is also the timing to determine business expectations, the objectives for collaborative business and to determine and prepare or adapt needed processes, resources and actors to be able to properly offer the core competence within an EN. During the formation phase, 
after a business opportunity appeared and the customer needs and requirements are determined, contract specific activities for organisational linkage of selected partners and competences can be performed by synchronising and harmonising of the identified processes, resources and actors. Linkage of partners by their competences facilitates a proper EN structure and the identification of interdependencies. Process instructions for interorganisational collaboration on the management of interfaces, can be implemented within a running quality planning in the QMS. The operation phase of EN offers the possibility to follow and monitor the created EN in terms of organisational structure/interdependencies and process orientation/interfaces. Therefore existing and applied methods implemented within existing QMS to measure the effectiveness and efficiency of processes can be used to attain network and quality objectives. The last phase of the life-cycle model of EN, the dissolution phase offers ideally the opportunity to take up gained knowledge during the operative monitoring and use it to improvement future collaboration preparation and operational activities. Potential suggestions for improvement can be retained and flow in quality planning issues in the preparation phase of an EN. This way a continuous improvement process can be realised even in temporarily business conditions like in EN.

\section{Outlook}

Companies are adopting new organisational forms that incorporate some level of 'virtuality' and 'modularity', that is, allowing certain processes to be performed outside the boundaries of the own company, and involving inter-organisational relationships at a deeper level than the traditional supplier-customer relationship. Such relationships might be characterised by short-term, temporary alignment of operations in EN where core competences of different actors are combined in a job-oriented fashion for a defined period. In this context, inter-organisational processes gain in importance when compared to the intra-organisational processes [14].

To transform customer requirements and to manage information in interorganisational EN will require a shift in focus from the way the companies allocate and structure their internal processes and resources towards the way it relates own processes and structures to those of the other counterparts in a network. Therefore QM approaches can be useful but they need to take the inter-organisational trend into account. For single companies it is necessary to identify possible connections and interdependencies between network members. To allow this, the next step for approaches or adaptations of available QM approaches is to ask companies to question existing structures and processes and study potential room for open structures and processes for smart harmonisation and synchronisation. The better the level of harmonisation and synchronisation can be realised the more reliable exchange of relevant information between the network members can be achieved and guaranteed. Identifying interdependencies in networks and adapting own core competencies to the networked environment, is necessary for organisations to finally guarantee complex customer demands in EN.

At the end the main goal will be to provide smart guidelines to quickly identify relevant business requirements from an EN, these are mostly interdependencies between core competences as communication content, and to model them more easily as 
operational processes and organisational structures. Modelled and well understood inter-organisational structures, resulting in communication structures with understanding of relevant content to be exchanged, help to guarantee a successful distribution of customer requirements through the entire value chain of an EN. Further approaches based on the concept developed within this work could help to provide more transparency on information exchange on the inter-organisational level and thus contribute to process quality and value in EN. This will help in turn to reduce the lack of information that is a risk for quality in collaborative business and finally leads to higher satisfaction of customers by providing the demanded product/service with planned quality and to the planned price, and in the planned time.

\section{References}

1. Seifert, M.: Collaboration Formation in Virtual Organisations by applying prospective Performance Measurement. Dissertation at the University of Bremen (2009)

2. Albani, A., Dietz, J.L.G.: Current trends in modelling inter-organizational cooperation. Journal of Enterprise Information Management 22(3), 275-297 (2009)

3. Jones, G.R., Bouncken, R.B.: Organisation, Theorie, Design und Wandel, 5th edn. Pearson Studium Verlag (2008) (in German)

4. Vahs, D.: Organisation - Einführung in die Organisationstheorie und praxis, 6th edn. Schäffler-Poeschel Verlag, Stuttgart (2007) (in German)

5. Binder, M., Clegg, B.T.: Enterprise management: a new frontier for organizations. International Journal of Production Economics 106(2), 406-430 (2007)

6. Robinson, C.J., Malhotra, M.K.: Defining the concept of supply chain quality management and its relevance to academic and industrial practice. International Journal of Production Economics 96, 315-337 (2005)

7. Sitek, P., Seifert, M., Thoben, K.-D.: Qualitätsmanagement in dynamischen Unternehmensnetzwerken - Anforderungen an Qualitätsmanagementsysteme. Industrie Management 4, S.25-S.28 (2010) (in German)

8. Paetau, M.: Virtuelle Unternehmen zwischen Interaktion und Organisation. In: Boos, M., Jonas, K.J., Sassenberg, K. (Hrsg.) Computervermittelte Kommunikation in Organisationen, Göttingen, pp. 129-141 (2000) (in German)

9. Thoben, K.-D., Jagdev, H.S.: Typological Issues in Enterprise Networks. Journal of Production Planning and Control 12(5), 421-436 (2001)

10. Vahs, D.: Organisation: Einführung in die Organisationstheorie und -praxis. SchäfferPoeschel Verlag, Aufl., Stuttgart (2007) (in German)

11. Sitek, P., Graser, F., Seifert, M.: Partner profiling to support the initiation of collaborative networks. In: Pawar, K.S., Thoben, K.-D., Pallot, M., Sophia-Antipolis (eds.) Proceedings of the 13th International Conference on Concurrent Enterprising, Concurrent Innovation: an Emerging Paradigm for Collaboration \& Competitiveness in the Extended Enterprise, pp. 213-220 (2007)

12. Sitek, P., Seifert, M., Thoben, K.-D.: Towards inter-organisational perspective to manage quality in temporary enterprise networks. International Journal for Quality and Reliability Management 27(2), 231-246 (2010)

13. N.N.: ISO 9001:2008 - Quality Management Systems - Requirements (2008)

14. Petridis, K.D.: Qualität in der Informationsgesellschaft - Die Rolle der Qualität in virtuellen Unternehmen und E-Commerce-Strukturen. In: QZ - Qualität und Zuverlässigkeit (2001) (in German) 